\title{
An appraisal of methods of testing some physical properties of sandcrete blocks
}

\author{
O. J. UZOMAKA
}

Mr M. Ben-George, University of Science and Technology, Kumasi. Ghana

A standard test in a code of practice must ensure that results are reproducible and that reasonable correlation can be made with known properties of the material under investjgation. In the case of concrete products these two basic conditions can be satisfied only if tests are carried out under the same controlled environment, whether one finds oneself in an arid or a wet and humid climate. In West Africa the Hamattan season is very dry and near arid, and the rainy season is extremely wet and highly humid at times. Curing of concrete products in the open or even under a shelter at different times of the year may produce inconsistent results if such results are to be used for control purposes on production sites. It is thus unwise to exclude any standard test in which provision is made for controlled environment. The best curing environment for most concrete products is under water with a uniform temperature over a period. Whether such a curing environment affects adversely certain properties of a product is not very relevant provided correlation of the results obtained can be made with in situ results and a measure of the degree of efficiency on site obtained.

41. If it is known that a $25-40 \%$ reduction in strength occurs when sandcrete blocks are immersed under water over a period, then any test on immersed sandcrete blocks may be used as a control test if proper adjustments are made before any conclusions are drawn from the results.

Professor K. Thomas and Dr B. Chinsman, Fourah Bay College, University of Sierra Leone

The Paper brings into focus the difficulties inherent in drawing up codes of practice for the use of building materials in countries where enough information from researches into the properties of such materials is as yet not available.

43. Sandcrete has been in use throughout West Africa for over 50 years as a popular material for the preparation of building blocks. However, only in 1961 was the attention of researchers in the then West African Building Research Institute first drawn to the need for a systematic study of this material. ${ }^{10}$ Much research was done at Fourah Bay College 9.11 between 1962 and 1967 to encourage the drawing up of reliable standards for its efficient use.

44. It is gratifying to see the emergence of a draft code for sandcrete blocks from the NSO, ${ }^{1}$ and the lead taken in the Paper to point out certain short-comings in the proposals.

45. Experience at Fourah Bay College confirms the Author's findings that capping of hollow blocks before testing them gives strengths higher than the true strength and that presoaking of the blocks before testing leads to a reduction of strength, except that

Paper published: Proc. Instn Civ. Engrs, Part 2, 1977, 63, Sept., 625-639. 
DISCUSSION
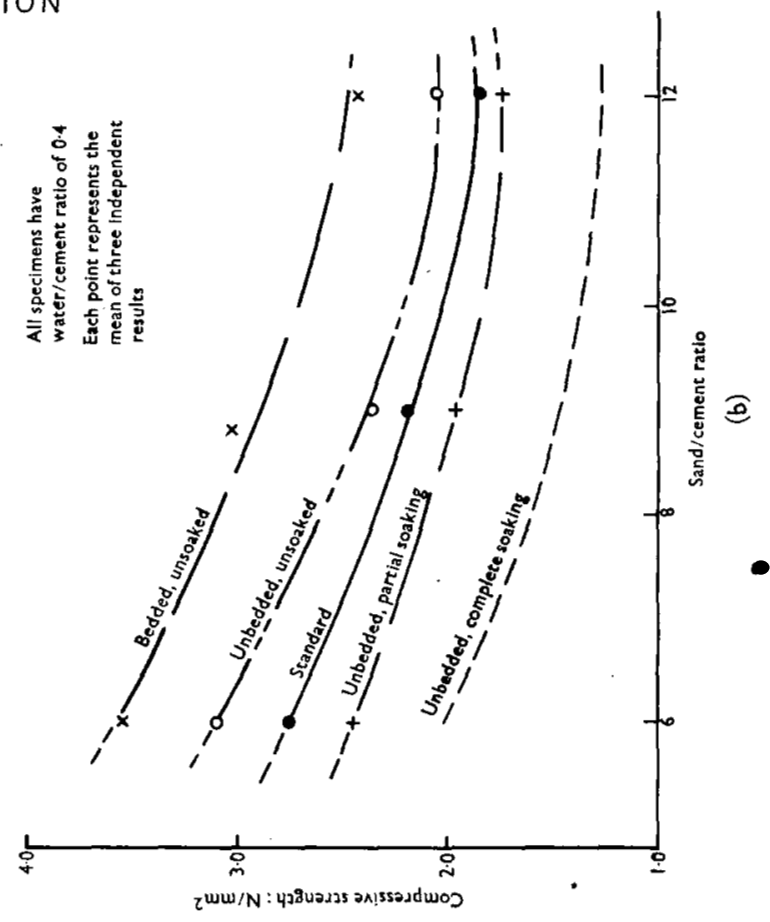

密

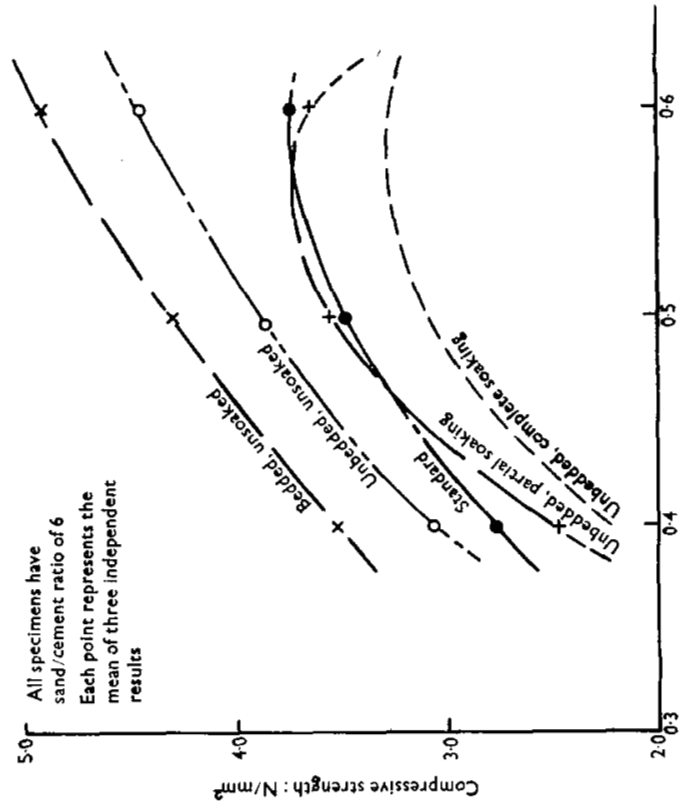

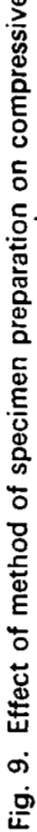

Downloaded by [] on [26/04/23]. Copyright (C ICE Publishing, all rights reserved. 
in tests made on solid blocks ${ }^{11}$ the reduction in strength due to wetting appeared to be about $9 \%$ and this strength loss diminishes with age, It seems that more results are required to establish the order of magnitude.

46. Using the data in Fig. 4 it can be shown that a worse case than that of the standard test is obtained for uncapped and soaked blocks (Fig. 9). It would therefore be more realistic in the case of a material with as variable characteristics as sandcrete, to use a test giving the lowest strengths.

47. There would in general be justification for adopting the procedures giving lower strengths because

(a) it is common practice with local contracts to lay sandcrete blocks in any state, wet or dry, once they have been delivered to the site

(b) during construction in the wet season certain external block walls carrying construction loads may become saturated through exposure to heavy rainfall.

48. The Author seems to feel that special tests are necessary to cater for these situations, but if such tests were devised they might prove more elaborate than the proposed NSO tests, because it would be necessary to subject the blocks to wetting and drying cycles. Special tests would be unattractive to standards organizations who would prefer to have one standard test and to vary instead the acceptance levels to suit the intended use of the blocks.

49. Any test proposal should be considered as an aim at establishing controls rather than a pronouncement on true strength. The important issue is that the final choice of test should be centred on the relationship which design recommendations should bear with the results of such tests. This relationship should be established as a standard relationship; its reliability is enhanced when it is drawn up against the lower limit of strength variation. Standard test methods should also aim at the facility to repeat identical testing conditions on all specimens or samples.

50. The procedure of rubbing down the test faces with caborundum plates has been found to give consistent results, but much care is required to achieve the desired even surfaces and it will depend on the calibre of technical personnel whether or not this care is exercised in all cases. The NSO procedure of capping ensures that special attention is given to providing smooth testing surfaces. Supplementary testing of the mortar of which the capping is made makes the procedure cumbersome and could be eliminated if a substitute capping material such as plaster of Paris were used.

51. The Paper suggests that the solid area of the hollow block rather than the capped area should be used in computing the compressive strength. The method presumes that the aspect ratio of hollow blocks will be controlled. In the absence of such controls evaluation of test results will be difficult.

52. The Author's reservations about the water absorption capacity test are noted. However, for his tests absorption capacity would vary markedly with humidity and temperature conditions during the period of manufacture or testing of the blocks. The question again reduces to one of reproducibility of the same testing conditions on all samples.

\section{Mr S. W. Norton (M)}

Further to $\S 9$, did the Author consider the use of softboard between the platens and the bedding faces as a rapid test method?

54. The capping of low-strength blocks with a $1: 1$ cement-sand mortar would appear to be a laborious process. A capping material of Portland cement and calcined gypsum in the proportions $2: 1$ by mass would allow rapid capping and testing. For high strength blocks a high alumina cement-sand mix of $1: 2$ would allow much earlier testing than Portland cement-sand capping.

55. Typical compressive strengths of capping mixes after 24 hours are
2:1 Portland cement-calcined gypsum
$1: 2$ high alumina cement-sand
$9 \mathrm{MPa}\left(\mathrm{N} / \mathrm{mm}^{2}\right)$
$32 \mathrm{MPa}\left(\mathrm{N} / \mathrm{mm}^{2}\right)$ 
Would the Author agree that presoaking before test is an attempt to achieve a measure of reproducibility?

56. With regard to $\$ 31$, if it is a requirement that blocks should not be built in until they are 28 days old and the period of drying is stipulated, then there is a case for making the linear shrinkage optional. If there is intrinsic instability of the aggregates then of course the drying shrinkage test is essential.

\section{Professor Uzomaka}

Mr Ben-George has emphasized the need for using standard specimens for quality control tests. Test results from standard specimens of concrete cast and cured in a specified standard manner are used during the construction stage, and serve two purposes: they give a measure of the consistency of the quality of the lumped mix variables and they give an indication of the potential strength which the concrete in the structure could attain.

58. If it is desired to obtain a closer estimate of the true strength of the concrete in a structure, a core is then drilled out from the structure and tested. This is because the result obtained from testing the core is considered more authentic than that obtained from testing specimens made and cured in a standard manner. The justification for this order of ranking is that the core represents the in situ state of the concrete in the structure, if stress relief considerations are ignored. Nevertheless, tests on standard specimens are used more frequently because cores are very expensive, and coring to obtain enough specimens to be representative could undermine the stability of the structural element. Moreover, concrete mix design is based on the results of laboratory tests on standard specimens.

59. The situation is apparently different with sandcrete blocks, these being precast units of sizes small enough to be amenable to direct testing. The blocks are often used seven days after moulding or even earlier. It should therefore be the aim of a code of practice for testing sandcrete blocks to ascertain as accurately as possible the strength of a block which is to be incorporated in a structure. The pertinent issue is acceptance testing, rather than quality control testing. Thus, the facts that the ambient conditions in West Africa vary between very dry and near arid to wet and highly humid, and that curing under such different conditions affects strength development, emphasize the importance of testing the blocks in their natural state, and not doing anything that would modify this natural strength.

60. Professor Thomas and Dr Chinsman have given detailed discussion of the strength testing aspect of the Paper. It had been found earlier ${ }^{4}$ that the compressive strength of sandcrete block is an exponential function of the average solid thickness of the block, i.e. the quotient of the solid bearing area to the sum of the lengths of the centre lines of the solid parts of the bearing surface. This factor is also likely to affect the reduction in strength due to soaking. Therefore, it is not surprising that there is such disparity between the reduction in strength of $25-45 \%$ in the Paper for the hollow block having an average solid thickness of $70.6 \mathrm{~mm}$ and the reduction of $9 \%$ for equivalent solid blocks with an average solid thickness of $225 \mathrm{~mm}$. Nevertheless, I support the view that more results are required to establish the orders of magnitude of strength reduction; the results would be more widely applicable and the exercise more expeditious if it were undertaken severally.

61. The suggestion in $\$ 21$ does not imply special wetting and drying cycle tests (\$48). What is required is simply to determine the compressive strengths of blocks after varying, but specified, degrees of soaking. In this way strength reduction factors corresponding to different degrees of wetting or soaking can be tabulated. Having done this, situations $(a)$ and $(b)$ in $\$ 47$ would be catered for, and the suggestion in $\S 46$ would be unnecessary because conditions $(a)$ and $(b)$ do not represent all possible states of blocks.

62. Referring to $\S 49$, the value of any control test is enhanced if it simulates a real 
situation. An indirect approach of correlating related parameters is generally a second best, after a direct simulation has proved very complicated and involved.

63. My criticism of capping is due to its stiffening effect, which could be overcome by capping only the solid parts as suggested in $\S 11$. It is possible also that plaster of Paris, even across the entire bedding face, may not give as much stiffening, and this suggestion is therefore worth trying.

64. The aspect ratio of a block does not feature in either equations (1) or (2) and it is therefore difficult to see the difficulty involved in the evaluation of compressive strength based on the solid area. However, it has been shown ${ }^{3}$ that there are two overall sizes of block (and therefore aspect ratio) used in Nigeria, but there are differences in the dimensions in plan (Fig. 2).

65. The comment on the approximate absorption test method is appreciated. The primary aim is to simplify the test for the local industry ( $\$ 24$ and 30 ).

66. In reply to Mr Norton, softboard was not used in the investigation, but the effect on block strength of interposing various types of material between the test specimen and machine is being considered.

67. It is true that presoaking aims at reproducibility, but reproducibility should not be of primary concern.

68. The requirement of $\S 56$ should refer to plastering rather than to building in before the blocks are 28 days old. As stated in $\$ 31$, block walls are rarely plastered before the blocks are 28 days old, in which case also they would have dried out for more than 28 days.

69. As sandcrete blocks contain only sand, cement and water, there should be no problems of instability.

\section{References}

10. TYLER R. G. Sandcrete blocks. West African Building Research Institute, 1961, Note 4.

11. ThомаS K. Influence of the curing conditions and mix proportions on the compressive strength of sandcrete blocks. Bull. R.I.L.E.M., 1964, New series, No. 24, Sept., 149-155. 